\title{
MASIFICACIÓN DEL INDIVIDUO E INAUTENTICIDAD EN EL DIÁLOGO
}

\section{Massification of the individual and inauthenticity in dialogue}

\author{
David Ricardo Andrade Mogrovejo* \\ Consultorio Psicológico Humanitas - Lima, Perú \\ https://orcid.org/0000-0002-3117-2193
}

\begin{abstract}
Resumen
El presenta artículo tiene como objetivo realizar un análisis sobre la problemática psicológica y social de la conversión del individuo en masa y acerca del diálogo inauténtico. Se dan a conocer los mecanismos psicológicos y sociales que despojan al individuo de su autenticidad y lo funden en la masa, se enfatiza también en la dificultad para establecer un diálogo auténtico con los otros como consecuencia de la enajenación de sí mismo y el conflicto de identidad. Así mismo, se toman en cuenta elementos como la pérdida de identidad, educación, autenticidad, libertad, responsabilidad, conciencia e intencionalidad, con el propósito de enriquecer el análisis en esta problemática. Para sustentar teóricamente el presente artículo, se empleó bibliografía basada en autores como Viktor Frankl, Ronald Laing, Rollo May, Soren Kierkegaard, José Ortega y Gasset, Carl Rogers, Byung Chul Han, Zygmunt Bauman, Emmanuel Lévinas, Miguel de Unamuno, Max Scheler, William Davies, Joan-Carles Mélich y Jean Paul Sartre. Como propuestas y conclusiones frente a esta problemática, se enfatiza en la construcción de una comunidad donde se acepten las diferencias entre individuos y se promueva un diálogo más auténtico entre personas a través del compromiso individual y la acción.
\end{abstract}

Palabras clave: Autenticidad, comunidad, diálogo, inautenticidad, masa.

\begin{abstract}
The aim of this article is to analyze both the psychological and social problems involved in the conversion of the individual into a mass, and inauthentic dialogue. The psychological and social mechanisms that deprive an individual of their authenticity and merge them into the mass are presented, also emphasizing the difficulty of establishing an authentic dialogue with others because of the alienation of oneself and the identity conflict. Likewise, elements such as the loss of identity, education, authenticity, freedom, responsibility, conscience, and intentionality are considered, with the purpose of enriching the analysis of this problem. A bibliography based on authors such as Viktor Frankl, Ronald Laing, Rollo May, Soren Kierkegaard, José Ortega y Gasset, Carl Rogers, Byung Chul Han, Zygmunt Bauman, Emmanuel Lévinas Miguel de Unamuno, Max Scheler, William Davies, Joan-Carles Mélich and Jean Paul Sartre was used as background for this study. As proposals and conclusions to face this problem, the article stresses the construction of a community where differences between individuals are accepted, and a more authentic dialogue between people is promoted through individual commitment and action.
\end{abstract}

Keywords: authenticity, community, dialogue, inauthenticity, mass.

Cualquier uso que se haga de este artículo debe incluir: Autor / Título original de la publicación / ISSN.

\footnotetext{
*Psicólogo. darianmo900@gmail.com
} 


\section{INTRODUCCIÓN}

El problema de la influencia de las masas en el individuo se manifiesta en diversos contextos, como ejemplo podemos tomar a las variadas manifestaciones populares, donde se suele observar que la gran mayoría de manifestantes tan solo siguen lo que los demás dicen o hacen. En una época donde abundan los "opinólogos" y las ideas vacías, o comentarios de los cuales un gran número de personas se apropia por la condición de ser "mayoría"; se hace necesaria la reflexión acerca de la transformación del individuo en masa, su pérdida de autenticidad, el diálogo inauténtico; y tomar como propuestas de solución la formación de una comunidad y diálogo auténtico.

\section{CÓMO SE TRANSFORMA EL INDIVIDUO EN MASA}

El hombre, al definirse como tal, ha de existir, encontrarse y surgir en el mundo (Sartre, 1992). En el encuentro consigo mismo y con el mundo, se va encaminando hacia un modo de ser auténtico y genuino. A lo que el mismo Sartre, se refiere como la definición que hace de sí mismo luego de impulsarse hacia la existencia. Es decir, la acción nos define como seres auténticos.

Se puede afirmar, entonces, que el hombre es responsable de sí mismo, y a su vez, también es responsable de todos los hombres (Sartre, 1992). Por lo que no se trata de querer solo nuestra libertad, sino que cuando nos referimos a nuestra libertad, también nos referimos a la libertad de los otros. Esta libertad también se refiere a la individualidad y autenticidad. Lo contrario ocurre cuando se habla de la transformación del individuo en masa.

En este sentido, cuando nos referimos a la libertad, inevitablemente apelamos a la figura del Otro, pues somos libres en la medida que los otros también son libres, por lo tanto, la libertad y la responsabilidad son dos caras de una misma moneda. Así mismo, cuando realizamos un acto en libertad siempre nos dirigimos a otro, tal como señala Lévinas (1998): "La Obra pensada radicalmente es en efecto un movimiento de lo Mismo que va hacia lo Otro sin regresar jamás a lo Mismo" (p. 54).
El fenómeno de las masas contribuye a la enajenación del individuo y al conflicto de la identidad; ya lo había mencionado May (1973), en palabras propias como un "resultado inevitable del colectivismo, la educación de masas, la comunicación de masas, la tecnología de masas y otros procesos de masas que configuran el pensamiento y las emociones de la gente actual" (p. 48). La influencia de estos procesos de masas tiene un fuerte impacto en la propia originalidad del individuo, afectándose el pensamiento y las emociones.

Los procesos de masas, al desencadenar conflictos de identidad en la sociedad moderna, también generan desesperación en el individuo. Esta desesperación, de la que Kierkegaard (2009), también hace referencia, implica desesperar en la figura de sí mismo, por lo que el hombre desea deshacerse de sí mismo mientras siente la desesperación. Toda crisis de identidad implica incertidumbre y desesperación del individuo. Entonces, cuando se producen estos conflictos de identidad, la angustia del vacío u horro vacui (Frankl, 2003), impulsa al individuo a llevar un ritmo acelerado en su vida como cura frente a la frustración existencial que vive. Es decir, la angustia del vacío aparece cuando el individuo desespera al no encontrar su lugar en el mundo y surge la necesidad de pertenecer a un colectivo o de fundirse en la masa.

Así mismo, los procesos de masas, tales como la educación, el colectivismo, la comunicación y la tecnología, se encargan de configurar las emociones y el pensamiento del individuo moderno, tal como lo plantea May (1973). Dichos procesos crean individuos robotizados e inauténticos, no se guían de una misión personal de vida, tienden a girar de acuerdo al colectivo o al de una máquina que les exige rehacerse según la imagen de ella, pues ya no hay un mito positivo que los pueda guiar.

El dilema que genera esta pérdida de identidad es producto del período histórico transicional, donde el poder impersonal ha generado como consecuencias la disminución de la conciencia humana y de la responsabilidad. Así mismo, el intento de anular la conciencia y la responsabilidad producen episodios de ansiedad, que expresan el "fracaso del sentimiento de significación del hombre como individuo $y$, 
consecuentemente, la pérdida de su capacidad para la decisión y la responsabilidad individual" (May, 1973, p.54). La sensación de ausencia de significación del hombre como individuo concluye en el declive de la libertad y la responsabilidad, lo que también incrementa la ansiedad.

Frente al problema de la pérdida de identidad, surge el deseo de pertenecer a un grupo homogéneo, donde el individuo quiere sentirse valorado, pues no ha construido auténticamente su identidad como consecuencia de los poderes impersonales que no le permiten desarrollarse íntegramente como ser humano. Sin embargo, tal como menciona Scheler (1994), el hombre es "libre frente al mundo circundante" (p. 48), por lo tanto, está obligado a responder frente a estas fuerzas impersonales condicionantes haciendo uso de su libertad.

La pérdida de identidad se refleja en el sentimiento de no importarle a nadie, creándose una situación de impotencia e insignificancia propia. Entonces, como consecuencia, sobreviene la apatía y la confusión, expresándose como la disminución del estado de conciencia, por lo que el individuo pretende obligar al sistema a reconocerlo, admitirlo y darse cuenta de su poder (May, 1973). La disminución del estado de conciencia implica no pensar por sí mismo y favorece la masificación del individuo ante la impotencia generada por las autoridades impersonales.

La apatía también surge como consecuencia de la ansiedad, por lo que al prolongarse evoluciona en un embotamiento emocional que concluye con un proceso de despersonalización. Esta despersonalización, producto de la carente identidad o la sensación de no existir para nadie, también radica en la ausencia de valores accesibles en la cultura moderna, lo que se considera como la base fundamental para relacionarse con el mundo externo (May, 1973). Así mismo, la ansiedad se genera como producto de la amenaza a los valores con los que un individuo se identifica, sean éstos de carácter social, emocional o moral. La crisis de identidad también se puede considerar como una crisis de valores, pues el conjunto de valoraciones conforma la identidad, y al generarse un conflicto en ello, puede desviarse hacia la masificación.
Otro punto importante es el papel de la tecnología, del uso masivo de la tecnología. Nos podemos preguntar cómo es que este uso se ha convertido en una necesidad. La respuesta radica en el uso autodestructivo de algunas tecnologías para combatir el vacío de la conciencia en sí (May, 1973), de esta manera se puede plantear que las tecnologías de masas actúan como una medicina para el dolor emocional, sin embargo, alienan al ser humano de sus valores, lo desvían de su misión personal y lo convierten en una parte de la gran masa.

Con respecto a la alienación frente al dolor emocional, Frankl (2014), refiere que el hombre en busca de su felicidad se impide a sí mismo ser feliz, pues convierte el efecto de la autotrascendencia en el objetivo final de la intención. Es decir, la felicidad no debe ser el objetivo final de las acciones, sino que debe surgir como consecuencia de la trascendencia que logramos a través del acto intencional.

En este sentido, Davies (2015) afirma que el mismo Estado se reorienta hacia un excesivo optimismo, el cual se encarga de promocionar el placer y disminuir el sufrimiento. Frente a ello, surgen nuevas filosofías de vida o pseudopsicologías como el coaching, las cuales alienan al hombre de su autenticidad frente al dolor. Por lo tanto, el hombre debe girar hacia una mirada auténtica de sí mismo frente a los otros para evitar fundirse en la masa.

\section{LA PÉRDIDA DE LA AUTENTICIDAD EN LA MASA}

Los valores y las tradiciones, al considerarse inútiles y perder vigencia, llegan a desubicar al individuo de su mundo, pues pierden la base afectiva en la que solían apoyarse (May, 1973). Esta dificultad para ubicarse en el mundo forma parte de un período de transición, sin embargo, surge la pregunta de hacia dónde nos dirigimos como seres auténticos.

Entonces, como consecuencia surge un modo de lucha por los valores humanos, la propia imaginación y la conciencia misma (May, 1973). La reacción ante la pérdida de lo que se considera significativo en la existencia del individuo cobra un rol fundamental en el camino por no perder la autenticidad. Así mismo, este 
sentimiento de insignificancia como seres particulares se manifiesta en el debilitamiento del sentido de la responsabilidad, lo que inevitablemente afecta la libertad humana.

Esta ausencia de respuesta ante las preguntas de la vida bloquea el despliegue de la libertad dejando de lado la propia autenticidad, dando paso al involucramiento dentro de los fenómenos de masas. Entonces, la pobre gestión individual frente a la pérdida de los valores concluye con la formación de un hombre-masa.

Así mismo, la disminución de la autoconciencia implica una pérdida en el sentimiento de significación propia, donde el hombre ya no sabe que tiene una historia (May, 1973), ya no se percibe como un ser histórico, por lo que no se puede afirmar y valer en una acción propia al no haber confianza en la propia significación. Toda acción implica la conciencia de sí misma como acto intencional, y esta confianza declina en la no percepción de la propia historia.

El hombre que no se percibe como alguien con significación propia se enajena de sus propios recuerdos e historia. Al respecto, Ricoeur (2000), afirma que cuando uno se acuerda de algo es porque debe ir en busca de ese recuerdo, el cual presenta un carácter afectivo que se percibe como objeto de una búsqueda. El individuo que se enajena de su historia no se dirige hacia la búsqueda de sus recuerdos, por lo tanto, no se afirma auténticamente en el mundo pues deja de lado su identidad.

Del mismo modo, el alejamiento de las tradiciones genera una pérdida valorativa en la vida del individuo, la cual solo puede abastecerse con nuevos propósitos vitales que se encuentran en el mundo externo, tal como lo menciona Frankl (2014), en palabras propias: "estar siempre dirigido o apuntando hacia algo o alguien distinto de uno mismo: hacia un sentido que cumplir u otro ser humano que encontrar, una causa a la cual servir o una persona a la cual amar" (p. 36). Por lo tanto, mientras la persona sigue con vida siempre habrá un propósito que deba cumplir, por lo que siempre aparecen nuevos propósitos hasta la finitud.

Dentro de todo este problema, también se toma en cuenta el papel de la tecnología, la cual es utilizada como un medio para escapar de la ansiedad, sin embargo, termina por ponerlo más ansioso, aislado y alienado, pues limita su autoconciencia y la percepción de su significación (May, 1973). La tecnología termina siendo una de las mayores fuentes de ansiedad y alienación en el hombre moderno, a pesar de utilizarse para eliminar la ansiedad; así mismo, aliena al hombre porque no le permite desarrollar su autoconciencia.

Han (2012), menciona, al respecto, que el exceso de positividad y el rechazo por la negatividad de lo extraño que se vive en la sociedad actual se manifiesta en diversas enfermedades de tipo neuronales. La idea del éxito implica autoexigencia por parte del individuo, por ello, sociedades arraigadas a una cultura del éxito académico y laboral como la japonesa, presentan al suicidio como la principal forma de muerte en personas de 15 a 39 años (Wang y Wakatsuki, 2020).

Con respecto al rechazo por la negatividad de lo extraño, las diferencias que nos hacen seres humanos únicos e irrepetibles son apartadas para abrazar lo idéntico, reacción que se manifiesta en situaciones sociales, familiares, académicas y laborales. De la misma manera, la búsqueda de lo idéntico se relaciona con el exceso de positividad, pues se apunta hacia un mismo ideal del éxito que se puede lograr autoexigiéndose cada vez más. Por lo tanto, el individuo se percibe obligado a lograr las metas impuestas por las autoridades impersonales y no perdona el fracaso o la caída.

El saberse diferenciar del Otro es necesario para que exista comunidad, encontrar un propósito en la vida y aceptar el fracaso y las situaciones adversas. Tal como menciona el sociólogo Bauman (2009), el "nosotros" no representa un plural del "yo", más bien se trata de un vínculo entre unidades totalmente desiguales. La cultura posmoderna del éxito rechaza estos aspectos humanos y como reacción se manifiestan diversos problemas psicológicos.

Por otra parte, también influyen los criterios de evaluación que toman en cuenta las instituciones educativas, reemplazando la percepción valorativa del estudiante por una valoración externa, lo que disminuye la autoconciencia y socava la experiencia personal (May, 1973); el mejor ejemplo sería tomar en 
cuenta el puntaje de la calificación como valoración general del estudiante, lo que termina siendo engañoso tanto para el estudiante como para el docente. Se puede decir, entonces, que la externalización de la educación influye en el sentimiento de identidad de los estudiantes, siendo una causa de ansiedad para ellos. Así mismo, al perderse la experiencia del Yo, también se pierde progresivamente la sensibilidad estética y espiritual, incrementándose la ansiedad neurótica. Por ende, la imposición de ciertos criterios externos limita la libertad y responsabilidad del individuo, entonces surge la pregunta ¿cómo combatir este error en la educación?

La solución ante este problema podría partir del hecho que el individuo, a pesar de las imposiciones del sistema educativo, puede preservar su humanidad y su propio espíritu; sin embargo, ello implica tomar una postura de cinismo para no caer en la apatía mientras va desarrollando sus propios valores (May, 1973). Ello significa ignorar las imposiciones del sistema sin salirse de él, lo que también implica ser uno mismo dentro del sistema; puesto a que de todas maneras estamos relacionados con el mundo y sus valoraciones.

Frente a este problema, Mélich (2003), propone una educación desde el punto de vista literario, enfatizando en la diferencia entre la acción educativa y la adoctrinadora, proponiendo la inclusión de la lectura de textos narrativos y literarios como un valioso instrumento para educar en la ética. Con una educación literaria, el individuo enriquece su imaginación y ello le genera la posibilidad de crear orientaciones de sentido en su vida.

De esta manera, la educación desde el punto de vista literario se distancia de la educación religiosa, tecnológica y metafísica, pues no trata de imponer verdades reveladas, comprobadas ni racionales. Por lo tanto, en este proceso educativo se debe formar la razón imaginativa que va a permitir la narración y creación de los sentidos de vida del individuo.

Así mismo, la razón literaria se abre frente a la sorpresa, incertidumbre, cambio y a lo que le acontece al Otro, pues esta ética se basa en una relación de alteridad donde abre paso hacia una razón estética y compasiva frente al sufrimiento del Otro. Entonces, la educación es un modo de entregarse al Otro, de cuidarlo y acompañarlo en su proceso de transformación auténtica.

Por otra parte, el individuo, al encontrarse en una posición falsa, puede no darse cuenta de que se encuentra en esta posición; solo puede tomar conciencia de ello si es que no está completamente divorciado de su experiencia y de sus actos (Laing, 1974), por lo que, en este sentido, concuerda con la propuesta de Rollo May. De esta manera, el individuo puede diferenciar su experiencia personal de la posición que adopta ante una situación.

Sin embargo, quien no puede darse cuenta de la posición falsa que adopta ante las circunstancias se pierde de vista a sí mismo, ya no puede proyectarse, se desubica, no encuentra su posición en el mundo, llega al punto de desesperar, sin importarle el tiempo y el lugar donde se encuentra ubicado (Laing, 1974). No existe una direccionalidad para quien ha perdido su posición en el mundo, por lo que los actos que lo determinan no son genuinos, carecen de autenticidad.

Ya mencionaba Kierkegaard (2009), que el hombre desespera cuando ignora poseer un yo, cuando no quiere ser sí mismo y cuando quiere ser sí mismo. Por lo que el hombre desespera ante la insignificancia de su existencia, ante la negativa de verse como un ser auténtico.

También se puede hablar de una significación inauténtica cuando se renuncia a la propia significación para obtener significación para los otros. Esta significación inauténtica sirve como una armadura que protege del aislamiento y las burlas (May, 1973), lo que es manifestación de la limitación de la autoconciencia y de la no percepción de su propia historia.

También se toma en cuenta, en palabras de Laing (1974, p. 124), el hecho de que "el yo se puede atribuir a sí mismo o al otro, acciones con carácter de reveladoras u ocultadoras, vigorosas o débiles, plenas o vacías, y que harán real el ser del agente, haciéndolo más irreal, más creativo o destructivo". Por lo que se puede creer que la persona se presenta frente a otros tal cual es, sin embargo, existe la posibilidad de que constantemente usen máscaras para cubrir su identidad. 


\section{EL DIÁLOGO INAUTÉNTICO DE LAS MASAS}

Al tomar en cuenta a las fuerzas impersonales que nos rigen, es necesario conocer los efectos que generan, tales como la negación del sentimiento o la pérdida de la sensación de relacionarse con su mundo interpersonal, lo que progresivamente va a generar la ansiedad destructiva (May, 1973). La negación del sentimiento es la negación de los valores propios, de lo que se percibe como significativo para uno mismo; entonces nos presentamos frente a los otros como seres inauténticos, lo que va a generar un diálogo inauténtico con los otros.

En el ámbito educativo, también se niega la originalidad de los estudiantes, no se toma en cuenta la imaginación individual debido a su poca utilidad pragmática; sin embargo, la imaginación nos permite relacionarnos y crear nuestro mundo interior, nos permite vivenciarnos con los otros y con el mundo, siendo el mejor camino para conocer nuestra identidad (May, 1973). Solo a través de la creatividad y la imaginación se puede conocer la identidad, se puede ser consciente de sí mismo y no fundirse en la masa.

De acuerdo con Ortega y Gasset (1975), las masas "no deben ni pueden dirigir su propia existencia, y menos regentar la sociedad" (p. 47), pues las masas son inconscientes, no existe una direccionalidad en su accionar, actúan como si fueran marionetas de una entidad superior.

Hoy en día también se suele notar en los medios la creencia de tener derecho a la opinión sin realizar esfuerzo alguno para ejercer dicho derecho, como resultado se dan opiniones pobres y vagas acerca de un tema en específico. A este modo absurdo de ser, Ortega y Gasset (1975), lo denomina masa rebelde, que en cierto sentido sería tener el alma hermética, dirigiéndose al hermetismo intelectual, puesto a que la persona se considera intelectualmente completa con las ideas que posee, se conforma con ellas y no profundiza más allá. Este hombre, al ser vanidoso, se siente perfecto, llegando él mismo a considerar su idea de perfección como problemática, imaginaria y ficticia. Su hermetismo no le permite notar su insuficiencia ni compararse con los demás puesto a que no puede trascender más allá de sí mismo, se encuentra encapsulado.
Ya Ortega y Gasset (1975), refería que la masa no anhela convivir con lo que es diferente a ella, pues el mayor ejemplo se da cuando se trata de eliminar o reducir a todo grupo que se opone ante lo que esta manda. Entonces la masa manipula para hacerse dueña de una supuesta verdad absoluta, negando todos aquellos postulados con los que no concuerda.

Laing (1974), refiere que las personas suelen ponernos y ponerse a ellos mismos en una posición falsa, en este caso, pueden ser fácilmente manipulados para caer en la masificación, son vulnerables a formar parte de la masa. Tomando esta postura, el mismo autor señala en palabras propias: "ser auténtico es ser verdaderamente uno mismo, ser lo que se es, ser genuino. Ser inauténtico es no ser uno mismo, falsearse a sí mismo: es ser como no se es, una falsificación" (p.120). En otras palabras, hay falsificación cuando se cae en la inautenticidad, direccionando al individuo hacia la masa, una masa inconsciente que se caracteriza por la ausencia de la propia direccionalidad.

\section{¿MASA O COMUNIDAD?}

Para comprender la diferencia entre masa y comunidad, se debe tomar en cuenta que la conciencia colectiva implica un sentimiento comunitario, donde los individuos aportan sus diferencias en lugar de fundirse en lo idéntico, de esta manera se crea una comunidad de seres individuales. Unamuno (1982), refiere en propias palabras que "somos los hombres a modo de glóbulos de la sangre de un Ser Supremo que tiene su conciencia colectiva personal, la conciencia del Universo" (p. 139). La conciencia colectiva es contraria a la masa, la masa es inconsciente, la conciencia colectiva es la suma de las conciencias individuales de cada persona, teniendo la condición de ser únicas e irrepetibles cada una de ellas.

El filósofo español también nos propone que lo que nos une como seres para formar parte de una comunidad o colectivo es el amor espiritual, el cual se logra cuando las personas sufren juntos un mismo dolor, es decir, cuando se compadecen también se aman. La compasión permite la ayuda mutua entre seres humanos, lo que fortalece un sentimiento comunitario. 
Por otra parte, tenemos la propuesta de Sartre (1992), donde la responsabilidad y el compromiso giran en torno a la libertad para elegir, es decir, al tener esta facultad no sólo nos referimos a nosotros mismos, sino también a los otros. El hombre elige pensando en sí mismo y en el Otro, elige comprometiéndose con los otros porque con sus actos crea la imagen del hombre que quiere ser. Se puede decir que, al elegirse, también elige a todos los hombres. En una comunidad, cada hombre es libre y responsable por sus actos, puesto a que el compromiso está basado en el bien de la humanidad. El filósofo francés menciona en sus propias palabras que "así soy responsable para mí mismo y para todos, y creo cierta imagen del hombre que yo elijo; eligiéndome, elijo al hombre" (p. 18).

Entonces, la construcción de lo universal se da a través de la elección, tomando en cuenta el proyecto de cualquier otro hombre (Sartre, 1992). Lo universal, que difiere de la masa, se construye con los proyectos individuales de cada hombre gracias a la libertad y al compromiso, donde al desear mi libertad, también deseo la libertad de los otros.

Comprometerse con la humanidad para formar una comunidad es trascender. El hombre, al perderse fuera de sí mismo y proyectarse, persigue fines trascendentales (Sartre, 1992). Se relaciona con el mundo desde su propia individualidad y trasciende cuando concretiza su proyecto. Este proyecto se puede concretizar a través del trabajo, espacio en el que surge el lazo entre la peculiaridad del individuo y su comunidad, alcanzando su sentido y valor (Frankl, 1978).

Para May (1973), nuestro período histórico de transición se caracteriza por los procesos de masas, a los cuales se refiere como síntomas del empobrecimiento de la conciencia humana de nuestro tiempo, en cierto modo también expresa la lucha del hombre por resolver sus propios dilemas en este mundo moderno.

El acto y la predisposición de seguir lo que la masa impone se relaciona con el énfasis que pone la educación en la productividad, dejando de lado la importancia en la preparación para el coraje que conlleva la existencia y la posibilidad de estar solo, donde el individuo puede preparase mejor en el desarrollo de sus propias actitudes, en la reflexión y el pensamiento propio (May, 1973). El mismo psicoterapeuta señala que es la máquina la que produce, mientras que el hombre se encarga de crear. El acto creativo nos hace humanos, nos permite percibir las significaciones y encontrar el sentido a lo que realizamos. Si tan solo nos dedicamos a producir, caemos en el modo de ser inauténtico y nos fundimos en la masa.

Ortega y Gasset (1975), refiriéndose al problema de las masas y las aglomeraciones, señala lo siguiente:

Sencillísima de enunciar, aunque no de analizar, yo la denomino el hecho de la aglomeración, del lleno. Las ciudades están llenas de gente. Las casas, llenas de inquilinos. Los hoteles, llenos de huéspedes. Los trenes, llenos de viajeros. Los cafés, llenos de consumidores. Los paseos, llenos de transeúntes. Las salas de los médicos famosos, llenas de enfermos. Los espectáculos, como no sean muy extemporáneos, llenos de espectadores. Las playas, llenas de bañistas. Lo que antes no solía ser problema, empieza a serlo casi de continuo: encontrar sitio. (p. 48)

Entonces, encontrar sitio se convierte en una necesidad y surgen las aglomeraciones, las cuales no optan por una propia direccionalidad, solo siguen hacia donde se dirigen las masas y se funden en ellas. El mismo Ortega y Gasset (1975), refiere que anteriormente los individuos vivían en pequeños grupos, distantes cada uno de ellos, cada uno ocupaba su sitio, es decir, no existían las muchedumbres. En la sociedad actual encontramos minorías y masas, donde las minorías son individuos cualificados y las masas no son especialmente cualificadas, pues su concepto es de carácter cuantitativo y visual. La masa es el hombre común, su única determinación cualitativa es lo común, pues no se diferencia de otros hombres, presenta un exceso hacia lo idéntico, en términos de Han (2012).

Por otra parte, las minorías se forman en base a un ideal o deseo que los excluye de la masa, un deseo relativamente individual, en el que tan solo coinciden con los otros miembros del grupo minoritario en el hecho de no coincidir (Ortega y Gasset, 1975). A partir de esta condición cualitativa de la no coincidencia, 
cada hombre aporta su proyecto individual para formar una comunidad.

El ya mencionado filósofo español señala que en la constitución de la masa se encuentra todo aquel que no se valora a sí mismo, aquel que quiere sentirse como todo el mundo se siente y se encuentra temeroso frente a la angustia que implica ser diferente y único. Sentirse idéntico a los demás disminuye su angustia. Lo señala en palabras propias cuando menciona que "hoy asistimos al triunfo de una hiperdemocracia en que la masa actúa directamente sin ley, por medio de materiales presiones, imponiendo sus aspiraciones y sus gustos" (1975, p. 53). La masa llega a destruir lo que es diferente e individual, quien no piense como piensa todo el mundo se encuentra en riesgo de ser eliminado. Pareciese como si el escenario del mundo fuera la masa, restando o eliminado la importancia de los grupos minoritarios.

Para el filósofo español, existe una gran confusión al considerar a una masa con posesión de cultura. Las masas tienen ideas, pero no son ideas auténticas, además de no admitir instancias reguladoras, es decir, no cumplen con normas, las cuales son los principios de la cultura. Un claro ejemplo lo podemos ver en el tan resonado dicho "tu opinión importa", donde diversos periodistas apelan al hecho "democrático" de opinar acerca de un tema específico a pesar de no poseer las bases de conocimiento sobre el tema. Estas bases de conocimiento vendrían a ser los principios de la cultura, el cual está regido por normas. De esta manera, cualquier "hombre común" podría ser capaz de realizar una crítica estética a una obra de arte o cualquier aficionado a literatura podría escribir una novela sin poseer la formación que se requiere.

El filósofo español añade, además, que las masas reconocen como norma a la acción directa. Se puede decir que actúan impulsivamente para lograr un objetivo, llegando a hacer uso de la violencia para un fin. Ejemplos podemos ver en las marchas masivas o en las barras bravas, donde se hacen presente estos actos retrospectivos.

\section{EL DIÁLOGO AUTÉNTICO}

Cuando hablamos de autenticidad, también nos referimos al descubrimiento de mi propia intimidad, a lo que Sartre (1992), señala como el descubrimiento del otro en ese preciso instante, pues el descubrimiento de mi intimidad es una expresión de la libertad, y como se mencionó anteriormente, si deseo mi libertad, también soy responsable de una libertad colocada frente a mí. Voy descubriendo al Otro en el momento en que me voy descubriendo. El filósofo francés señala al respecto: "así descubrimos en seguida un mundo que llamaremos la intersubjetividad, y en este mundo el hombre decide lo que es y lo que son los otros" (p. 33). La intersubjetividad nos permite establecer un diálogo más auténtico.

Para Rogers (1992), la persona siente miedo en su proceso de transformación a lo auténtico, a lo que realmente es. Al quitarse la máscara, se acerca a la posibilidad de ser sí mismo, ya no se oculta, se muestra tal cual es. La angustia frente al descubrimiento y aceptación de la autenticidad nos permite desplegar el yo, lo espiritual. Kierkegaard (2009), afirma que "el yo es una relación que se relaciona consigo misma, o dicho de otra manera: es lo que en la relación hace que ésta se relacione consigo misma" (p. 17). A partir de la relación consigo mismo, puede surgir la autenticidad del individuo para sí mismo y para con los otros.

Como consecuencia de la apertura hacia la autenticidad, se apunta al compromiso como movilizador de las acciones. Sin embargo, el individuo cuando se compromete es capaz de trabajar con la ansiedad que presenta, la usa constructivamente, llegando a relacionarse con la situación y comprometiéndose durante la acción (May, 1973). El compromiso y la acción hacen posible y fructífero el diálogo entre los individuos.

La tecnología es un recurso que puede ser útil hoy en día, sin embargo, también genera conflicto con los valores humanos al imponer el poder impersonal (May, 1973). Se requiere que los individuos, desde la escuela, aprendan el acto de valorar y perciban el contenido de los valores. En este sentido, la ansiedad se convierte en una capacidad interna para la elección de los valores en un momento determinado. 
Para lograr un camino hacia un diálogo más auténtico es necesario tener ideas en las cuales se poseen razones, lo que implica aceptar un código cultural establecido en normas (Ortega y Gasset, 1975). El filósofo español sostiene que el hombre-masa se sentiría perdido en una discusión, no habría lugar para el diálogo desde su postura, sino solamente para la acción directa. El diálogo también es un camino para una convivencia cultural, bajo normas, mientras que la postura de tomar una acción directa por parte del hombre-masa sería como un retroceso a la convivencia bárbara. Gracias al diálogo es que podemos conocer y aceptar al Otro con lo diferente que trae consigo, es una forma de apertura al mundo de los otros en nuestra condición de seres relacionales.

Ortega y Gasset (1975), hace énfasis en la civilización, la cual es el origen de la ciudad, la comunidad y la convivencia. Con todo ello se refiere al deseo progresivo de contar con las demás personas, tan solo en un estado de barbarie no se puede contar con los otros. En un estado de barbarie no existe el diálogo porque no hay voluntad de convivencia. El diálogo, al aceptar las diferencias y cualidades del Otro, construye la comunidad.

El diálogo auténtico también se fortalece a través de los actos, en palabras de Laing (1974), serían la culminación real de lo que se habla, se trata de ser yo mismo. El psiquiatra escocés además señala que "en la medida en que me meto dentro de lo que hago, haciéndolo llego a ser yo" (p. 121). La autenticidad del yo se va construyendo con los actos que vamos realizando.

\section{CONCLUSIONES}

Se puede concluir que para llegar a formar una verdadera comunidad y no fundirse en la masa, es necesario establecer el diálogo, el cual nos va a brindar las herramientas para aceptar y comprender las diferencias del Otro. Así mismo, se concretan con las acciones que realizamos, las cuales que permiten ser uno mismo, ser auténtico.

Del mismo modo, se requieren reformas en el paradigma educativo como la propuesta de Mélich (2003), sobre la educación desde un punto de vista literario. Este giro educativo centrado en la persona va a permitir la orientación hacia un propósito vital, como también el desarrollo de la sensibilidad frente a lo que le acontece al Otro.

Por último, es importante fomentar la comprensión y aceptación de las diferencias individuales, pues estas enriquecen el diálogo y brindan apertura hacia una convivencia auténtica. Así mismo, ayuda a desarrollar la imaginación y la empatía.

\section{REFERENCIAS}

Bauman, Z. (2009). Ética posmoderna. Siglo XXI de España Editores.

Davies, W. (2015). La industria de la felicidad. Cómo el gobierno y las grandes empresas nos vendieron el bienestar. Malpaso.

Frankl, V. (1978). Psicoanálisis y existencialismo: de la psicoterapia a la logoterapia.(2da Ed.). Fondo de Cultura Económica.

Frankl, V. (2003). Ante el vacío existencial. Hacia una humanización de la psicoterapia. (2da Ed.). Herder.

Frankl, V. (2014). Psicoterapia y humanismo. ¿Tiene un sentido la vida? (2da Ed.). Fondo de Cultura Económica.

Han, B. (2012). La sociedad del cansancio. Herder.

Kierkegaard, S. (2009). La enfermedad mortal o de la desesperación y el pecado. San José.

Laing, R. (1974). El yo y los otros. Fondo de Cultura Económica.

Lévinas, E. (1998). La huella del Otro. Taurus.

May, R. (1973). El dilema existencial del hombre moderno. Paidós.

Mélich, J. (2003). La sabiduría de lo incierto. Sobre ética y educación desde un punto de vista literario. Educar, 31: 33-45.

Ortega y Gasset, J. (1975). La rebelión de las masas. Universo.

Ricoeur, P. (2000). La memoria, la historia, el olvido. Fondo de Cultura Económica. 
Rogers, C. (1992). El proceso de convertirse en persona: mi técnica psicoterapéutica. Recuperado de https://jesuitas.lat/uploads/el-proceso-deconvertirse-en-persona/CARL\%20ROGERS\%20 -\%201992\% 20-\%20EL\%20PROCESO \% 20 DE\%20CONVERTIRSE\%20EN\%20PERSONA. pdf.

Sartre, J. (1992). El existencialismo es un humanismo. Palabra Gráfica y Editora.

Scheler, M. (1994). El puesto del hombre en el cosmos. (20ava Ed.). Losada.

Unamuno, M. (1982). Del sentimiento trágico de la vida. Espasa-Calpe.
Wang, S. y Wakatsuki, Y. (30 de Noviembre del 2020). En Japón, más personas murieron por suicidio el mes pasado que por covid en todo 2020. Y las mujeres han sido las más afectadas. ¿Por qué? . CNN Redacción. https://cnnespanol. cnn.com/2020/11/30/en-japon-mas-personasmurieron-por-suicidio-el-mes-pasado-que-porcovid-en-todo-2020-y-las-mujeres-han-sidolas-mas-afectadas-por-que/\#: : text=En $\% 20$ $2016 \% 2 \mathrm{C} \% 20 \mathrm{~J}$ a p \% C $3 \%$ B 3 n \% 20 ten $\% \mathrm{C} 3 \% \mathrm{ADa} \% 20$ una, $6 \% 20$ por $\% 20$ cada $\% 20$ $100.000 \% 20$ personas.

Fecha de recepción: 27 de mayo 2021

Fecha de aceptación: 16 de junio 2021 